\title{
Maternal vitamin D status, gestational diabetes and infant birth size
}

Helena H. Hauta-alus ${ }^{1}$, Heli T. Viljakainen ${ }^{1,2^{*}}$, Elisa M. Holmlund-Suila', Maria Enlund-Cerullo ${ }^{1}$, Jenni Rosendahl' Saara M. Valkama', Otto M. Helve', Timo K. Hytinantti ${ }^{1}$, Outi M. Mäkitie ${ }^{1,2,3}$ and Sture Andersson ${ }^{1}$

\begin{abstract}
Background: Maternal vitamin D status has been associated with both gestational diabetes mellitus (GDM) and fetal growth restriction, however, the evidence is inconsistent. In Finland, maternal vitamin D status has improved considerably due to national health policies. Our objective was to compare maternal 25-hydroxy vitamin D concentrations [25(OH)D] between mothers with and without GDM, and to investigate if an association existed between maternal vitamin $D$ concentration and infant birth size.
\end{abstract}

Methods: This cross-sectional study included 723 mother-child pairs. Mothers were of Caucasian origin, and infants were born at term with normal birth weight. GDM diagnosis and birth size were obtained from medical records. Maternal 25(OH)D was determined on average at 11 weeks of gestation in pregnancy and in umbilical cord blood (UCB) at birth.

Results: GDM was observed in 81 of the 723 women (11\%). Of the study population, 97\% were vitamin D sufficient $[25(\mathrm{OH}) \mathrm{D} \geq 50 \mathrm{nmol} / \mathrm{L}]$. There was no difference in pregnancy $25(\mathrm{OH}) \mathrm{D}$ concentration between GDM and non-GDM mothers ( $82 \mathrm{vs} 82 \mathrm{nmol} / \mathrm{L}, P=0.99$ ). Regression analysis confirmed no association between oral glucose tolerance test results and maternal $25(\mathrm{OH}) \mathrm{D}(P>0.53)$. Regarding the birth size, mothers with optimal pregnancy $25(\mathrm{OH}) \mathrm{D}(\geq 80 \mathrm{nmol} / \mathrm{L})$ had heavier newborns than those with suboptimal pregnancy $25(\mathrm{OH}) \mathrm{D}(P=0.010)$. However, mothers with optimal UCB $25(\mathrm{OH}) \mathrm{D}$ had newborns with smaller head circumference than those with suboptimal $25(\mathrm{OH}) \mathrm{D}(P=0.003)$, which was further confirmed as a linear association $(P=0.024)$.

Conclusions: Maternal vitamin D concentration was similar in mothers with and without GDM in a mostly vitamin D sufficient population. Associations between maternal vitamin D status and birth size were inconsistent. A sufficient maternal vitamin D status, specified as $25(\mathrm{OH}) \mathrm{D}$ above $50 \mathrm{nmol} / \mathrm{L}$, may be a threshold above which the physiological requirements of pregnancy are achieved.

Trial registration: The project protocol is registered in ClinicalTrials.gov in November 8, 2012 (NCT01723852).

Keywords: Maternal vitamin D status, Newborn vitamin D status, 25-hydroxy vitamin D concentration, Gestational diabetes mellitus, Birth size, Birth weight, Birth length, Head circumference, Ponderal index

\section{Background}

Vitamin D deficiency, defined as a circulating 25-hydroxy vitamin D (25(OH)D) concentration below $50 \mathrm{nmol} / \mathrm{L}$, has been common among Finnish pregnant women [1]. However, due to recent changes in national health policies, intake of vitamin $\mathrm{D}$ has increased resulting in

\footnotetext{
* Correspondence: heli.viljakainen@helsinki.fi

${ }^{1}$ Children's Hospital, University of Helsinki and Helsinki University Hospital,

Biomedicum 2 C, P.O. Box 705, 00020 HUS Helsinki, Finland

${ }^{2}$ Folkhälsan Research Center, Haartmaninkatu 8, P.O.Box 63, 00014 Helsinki,

Finland

Full list of author information is available at the end of the article
}

decreasing rates of vitamin D deficiency [2-5]. Vitamin D deficiency has been associated with gestational diabetes mellitus (GDM) [6], but the evidence is inconsistent $[7,8]$. Of all pregnancies, $1-14 \%$ are affected by GDM [9], and globally GDM prevalence has been increasing in line with increasing obesity [10]. GDM is the most common pregnancy complication in Europe [11]. In Finland, the prevalence of GDM has increased from 6\% in 2008 to $11 \%$ in 2014 [12]. GDM increases the risk of adverse pregnancy and neonatal outcomes, and the risk of obesity, metabolic syndrome, diabetes, and cardiovascular disease in later life both of the mother and the child [13]. 
Fetal growth may have later health implications also within the normal-birth-weight range [14]. Poor maternal vitamin $D$ status has been related to fetal growth restriction [15] but it is unknown whether maternal vitamin D status associates with birth size in infants with normal birth weight.

Many of the findings regarding the relationship between vitamin D deficiency and GDM are based on case-control studies, which may include a potential selection bias. Case-control studies often focus on high-risk groups, for example women who are overweight and sedentary, which are independent risk factors for vitamin D deficiency as well (for example [16]).

The objectives of the present study were to compare $25(\mathrm{OH}) \mathrm{D}$ concentration at two consecutive time points between mothers with and without GDM, and to investigate associations between maternal factors and infant's birth size, and the potential role of $25(\mathrm{OH}) \mathrm{D}$ concentration therein.

The study is part of the longitudinal Vitamin D Intervention in Infants (VIDI) study.

\section{Methods}

\section{Recruitment and study participants}

At Kätilöopisto Maternity Hospital, Helsinki, Finland, 987 families were recruited into the VIDI study between January 2013 and June 2014, after delivery during the mother's hospital stay. According to the inclusion criteria, the mothers were of Caucasian origin without regular medication and with singleton pregnancy. Exclusion criteria for the newborns were: nasal continuous positive airway pressure treatment >one day, intravenous glucose infusion, seizures, duration of phototherapy $>$ three days and need for nasogastric tube >one day. The infants were born between $37+0$ and $42+0$ weeks of gestation, and newborn's birth weight was appropriate for gestational age (SD-score [SDS] between -2.0 and +2.0 ). Of the recruited eligible families, $29 \%$ (987/3408) agreed to participate in the VIDI study. For the present cross-sectional study, we included mothers who had a record from a community prenatal clinic or baseline questionnaire and both two maternal 25(OH)D measurements. Two infants with a congenital disease (Down syndrome and Rieger syndrome) were excluded. Thus, the total number of subjects was 723. Of the infants, 367 were girls and 356 boys. Number of subjects in each analysis is reported in Tables.

\section{5(OH)D analyses}

Maternal pregnancy serum samples for 25(OH)D measurements were collected at community prenatal clinics at gestational weeks 7 to 25 between June 2012 and November 2013 as part of the mothers' normal follow-up [hereafter referred to as pregnancy $25(\mathrm{OH}) \mathrm{D}]$. At birth, umbilical cord blood (UCB) for 25(OH)D measurement was obtained at gestational weeks 37 to 42 between January 2013 and May 2014 [hereafter referred to as UCB 25(OH)D]. Both pregnancy serum and UCB plasma $25(\mathrm{OH}) \mathrm{D}$ were analysed simultaneously using the IDS-iSYS fully automated immunoassay system with chemiluminescence detection (Immunodiagnostic Systems Ltd., Bolton, UK). Detailed information on $25(\mathrm{OH}) \mathrm{D}$ analysis has been previously reported [5]. The quality and accuracy of the serum $25(\mathrm{OH}) \mathrm{D}$ analysis is validated on an ongoing basis by participation in the vitamin D External Quality Assessment Scheme (DEQAS, Charing Cross Hospital, London, UK).

Both $25(\mathrm{OH}) \mathrm{D}$ concentrations were corrected by applying a linear regression equation (Oct 2014 value $(\mathrm{nmol} / \mathrm{L})=[($ early 2014 value $)-8.2] / 0.99)$ provided by the manufacturer because of methodological changes in the IDS-iSYS system between 2014 and 2016 (see Additional file 1). We re-analysed a subsample of 77 samples and verified the correction (adjusted $R^{2}=0.922$, $\mathrm{SEE}=9.2 \mathrm{nmol} / \mathrm{l})$.

We employed UCB 25(OH)D to reflect both the maternal vitamin $\mathrm{D}$ status at the end of pregnancy and the newborn's vitamin $\mathrm{D}$ status at birth [1]. We defined vitamin $\mathrm{D}$ deficiency as $25(\mathrm{OH}) \mathrm{D}<50 \mathrm{nmol} / \mathrm{L}$, and vitamin D sufficiency as $25(\mathrm{OH}) \mathrm{D} \geq 50 \mathrm{nmol} / \mathrm{L}$, since a concentration of $\geq 50 \mathrm{nmol} / \mathrm{L}$ is considered sufficient for bone health [17]. Suboptimal vitamin D status was defined as $25(\mathrm{OH}) \mathrm{D}<80 \mathrm{nmol} / \mathrm{L}$, and optimal vitamin $\mathrm{D}$ status as $25(\mathrm{OH}) \mathrm{D} \geq 80 \mathrm{nmol} / \mathrm{L}$, as has been suggested based on calcium absorption studies [18].

\section{Maternal and newborn data}

Maternal data were obtained from a self-administered baseline questionnaire, filled in after delivery, and from medical records. Maternal height $(\mathrm{cm})$ and weight $(\mathrm{kg})$ before pregnancy and parity were collected primarily from the prenatal maternity card or, if missing, from our baseline questionnaire. Gestation was determined by first trimester ultrasound examination. Maternal age was determined at delivery. Parity was categorised into nullipara, secundipara and multipara (>two deliveries). Prepregnancy body mass index (BMI) $\left(\mathrm{kg} / \mathrm{m}^{2}\right)$ was categorised into underweight (<18.5), normal weight (18.5-24.9), overweight (25.0-29.9) and obese (>30.0).

Prepregnancy weight and weight recorded in prenatal clinics were utilised to calculate gestational weight gain (GWG) (kg). We recorded GWG at first measurement, at approximately the 12th, 20th and 30th gestational weeks, and at last measurement. GWG was adjusted for consecutive gestational week. Concerning the analysis of total GWG, absolute values were used, and women who had their final weight recorded more than three weeks before the delivery were omitted $(n=7)$. Total GWG was categorised into inadequate, adequate and excessive based on national recommendations by prepregnancy 
BMI: recommended GWG for underweight mothers was $12.5-18.0 \mathrm{~kg}$, for normal weight $11.5-16.0 \mathrm{~kg}$, for overweight $7.0-11.5 \mathrm{~kg}$, and for obese $5.0-9.0 \mathrm{~kg}$ [19].

Education level was graded from one (=comprehensive school/lower secondary education) to six (university degree/first or second stage of tertiary education). Education was re-categorised into 'lower' and 'higher' education (lower = lower or upper secondary or postsecondary non-tertiary education, higher $=$ first or second stage of tertiary education), due to a low number of subjects in other education categories. Prepregnancy smoking status was assessed as number of cigarettes per day. Maternal use of supplements, specific brand names, dosing, and date of commencement were recorded. We calculated the average daily intake of vitamin D from supplementation during the last two months of pregnancy.

Birth size, including birth weight $(\mathrm{kg})$, length $(\mathrm{cm})$, and head circumference $(\mathrm{cm})$, was measured by midwives according to standard procedure. These data and the duration of pregnancy were retrospectively collected from birth records. Birth size measures were transformed into SDS by using Finnish sex-specific normative data for fetal growth [20]. Ponderal index was calculated (birth weight $(\mathrm{kg}) /$ birth length $\left.(\mathrm{m})^{3}\right)$ and standardised into sex-specific z-score.

\section{Assessment of GDM}

The diagnosis of GDM was based on a two-hour $75 \mathrm{~g}$ oral glucose tolerance test (OGTT). According to the national guidelines, GDM was diagnosed if the OGTT results exceeded cut-offs for one or more values: fasting plasma glucose $\geq 5.3 \mathrm{mmol} / \mathrm{l}, 1-\mathrm{h} \geq 10.0 \mathrm{mmol} / \mathrm{l}$ and 2 $\mathrm{h} \geq 8.6 \mathrm{mmol} / \mathrm{l}$ [19]. An OGTT was performed at gestational weeks 10 to 40 between October 2012 and March 2014, and the results were collected from prenatal maternity cards or the hospital laboratory database. In general, screening for GDM depends on a presence of risk factors according to national recommendations [19] and based on these, OGTT was performed on 490 (54.5\%) of the participating mothers. None of the pregnant women in our study received insulin therapy nor other regular medication, but mothers with GDM obtained dietary counselling at community prenatal clinics [19].

\section{Statistical analysis}

The normality of the variables was visually inspected. Outliers $(n=18)$ of $25(\mathrm{OH}) \mathrm{D}$ concentrations were identified with Normal probability plot of residuals, Leverage and Cook's Distance diagnostic tests, and omitted from the analyses. Season with four categories affected maternal $25(\mathrm{OH}) \mathrm{D}$ concentrations. Thus, season at pregnancy blood sampling and at birth was coded using dummy variables (with autumn as a reference) in ANCOVA and used as a covariate.

The data included partially missing information. Imputation of missing values for education $(n=12)$ and parity $(n=2)$ were conducted using the median value in subgroups by GDM status. Missing data on prepregnancy smoking as number of cigarettes daily were imputed as a median value ( $=$ zero) by GDM status according to smoking status $(n=22)$. Imputation of missing values for GWG at 12 gestational weeks was conducted using a mean value of two consecutive measurements $(n=12)$. Missing values of other variables were not imputed. Maternal characteristics in Table 1 are described only as un-imputed values.

Independent sample t-tests, Mann-Whitney U-tests, repeated measures ANOVA or the Pearson Chi-Square test, when appropriate, were applied to compare maternal characteristics between GDM and non-GDM mothers. The difference in $25(\mathrm{OH}) \mathrm{D}$ between GDM and non-GDM mothers was investigated with ANCOVA adjusted for season, maternal age, education and prepregnancy BMI. Association between pregnancy 25(OH)D and OGTT results/birth weight, and between UCB 25(OH)D and head circumference at birth were tested with univariate linear regression. Prevalence of vitamin D deficiency in non-GDM and GDM mothers were tested with Fisher's Exact test.

Newborn birth size was investigated in categories of maternal prepregnancy BMI (underweight, normal weight, overweight, obese), GWG (inadequate, adequate, excessive), prepregnancy smoking status (yes, no), maternal education (higher, lower), parity (nullipara, secundipara, multipara), GDM status (yes, no), vitamin D status (suboptimal, optimal) in pregnancy and in UCB, with ANCOVA with Bonferroni correction when applicable, and adjusted for maternal height. Changing covariates appearing in the ANCOVA models were: prepregnancy BMI, GWG at last measurement, smoking, education, parity, GDM and $25(\mathrm{OH}) \mathrm{D}$ concentrations. Using both $25(\mathrm{OH}) \mathrm{D}$ concentrations as covariates in the GWG analysis induced a multicollinearity problem based on Cook's Distance and Levene's test, but excluding these covariates from the model did not change the results.

Results are shown as means or adjusted means with SD or SEM. The means and medians were similar in both vitamin $\mathrm{D}$ concentrations. Associations were considered significant at $P<0.05$. All statistical analyses were conducted using the IBM SPSS program for Windows, version 22 (IBM, Chicago, IL, USA).

\section{Results}

In the study population $97 \%$ were vitamin D sufficient $[25(\mathrm{OH}) \mathrm{D}>50 \mathrm{nmol} / \mathrm{L}]$ in both mothers and newborns, while optimal vitamin D status [25(OH)D above $80 \mathrm{nmol} / \mathrm{L}$ ] was seen in $52 \%$ of the mothers and $45 \%$ of the newborns. 
Table 1 Maternal characteristics in GDM and non-GDM mothers. P-values refer to differences between the groups

\begin{tabular}{|c|c|c|c|c|c|}
\hline Maternal characteristics & $n$ & Non-GDM & $n$ & GDM & $p$ value \\
\hline Age at delivery (y) & 642 & $31.4 \pm 4.3$ & 81 & $32.7 \pm 4.5$ & 0.018 \\
\hline Level of education ${ }^{a}$ & 632 & $5.0 \pm 1.3$ & 79 & $4.7 \pm 1.4$ & 0.051 \\
\hline Parity & 640 & $1.5 \pm 0.7$ & 81 & $1.5 \pm 0.7$ & 0.275 \\
\hline Prepregnancy smoking, number of cigarettes daily & 625 & $1.2 \pm 3.7$ & 76 & $2.0 \pm 4.6$ & 0.064 \\
\hline Alcohol consumption before pregnancy, portion/wk. & 625 & $1.9 \pm 2.0$ & 78 & $2.3 \pm 3.5$ & 0.755 \\
\hline Prepregnancy height $(\mathrm{cm})$ & 642 & $166.3 \pm 6.0$ & 81 & $165.9 \pm 5.4$ & 0.398 \\
\hline Prepregnancy weight (kg) & 631 & $63.5 \pm 10.2$ & 81 & $72.1 \pm 13.5$ & $<0.001$ \\
\hline Prepregnancy BMI $\left(\mathrm{kg} / \mathrm{m}^{2}\right)$ & 639 & $23.0 \pm 3.5$ & 81 & $26.2 \pm 4.8$ & $<0.001$ \\
\hline Duration of gestation at OGTT (wk) & 323 & $26.3 \pm 4.3$ & 80 & $25.9 \pm 5.9$ & 0.774 \\
\hline Duration of gestation at pregnancy blood sampling (wk) & 642 & $11.3 \pm 1.9$ & 81 & $11.2 \pm 2.2$ & 0.089 \\
\hline Duration of gestation at delivery (wk) & 642 & $40.2 \pm 1.1$ & 81 & $40.1 \pm 1.1$ & 0.410 \\
\hline Pregnancy 25(OH)D (nmol/L) & 642 & $81.9 \pm 19.5$ & 81 & $80.0 \pm 21.2$ & 0.417 \\
\hline UCB 25(OH)D (nmol/L) & 642 & $80.1 \pm 20.0$ & 81 & $78.4 \pm 18.8$ & 0.448 \\
\hline Supplemental vitamin D intake during pregnancy $(\mu \mathrm{g} / \mathrm{d})$ & 621 & $15.5 \pm 16.6$ & 76 & $13.5 \pm 10.8$ & 0.162 \\
\hline Cumulative gestational weight gain at ${ }^{\mathrm{b}}(\mathrm{kg})$ & & & & & 0.093 \\
\hline first measurement & 580 & $1.7 \pm 0.5$ & 74 & $1.6 \pm 0.5$ & \\
\hline 12th gestational week & 580 & $3.8 \pm 1.0$ & 74 & $3.6 \pm 1.1$ & \\
\hline 20th gestational week & 580 & $6.3 \pm 0.8$ & 74 & $6.2 \pm 0.8$ & \\
\hline 30th gestational week & 580 & $9.7 \pm 0.5$ & 74 & $9.7 \pm 0.4$ & \\
\hline last measurement & 580 & $13.8 \pm 0.4$ & 74 & $13.7 \pm 0.3$ & \\
\hline
\end{tabular}

GDM gestational diabetes mellitus, 25(OH)D 25-hydroxy vitamin $D, U C B$ umbilical cord blood Values are means $\pm S D$

${ }^{a}$ Scale from $1=$ lower secondary education to $6=$ first or second stage of tertiary education

${ }^{b}$ Values are adjusted for duration of gestation

Majority (95\%) of the mothers took vitamin D supplements during pregnancy, most of them were highly educated $(75 \%$ had at least a bachelor level education), and 73\% had normal weight before pregnancy.

\section{Vitamin D status and GDM}

In our cohort GDM was present in 81 of the 723 women (11\%). The comparison of maternal characteristics of GDM and non-GDM mothers is summarised in Table 1. Pregnancy 25(OH)D concentration was measured on average at 11 weeks of gestation, and GDM was diagnosed on average at 26 weeks of gestation in both GDM and non-GDM mothers. Mothers with GDM were older $(P=0.018)$, heavier and had higher prepregnancy BMI ( $P$ for both $<0.001$ ), and their educational level was at borderline of significance $(P=0.051)$ lower compared with mothers without GDM. No differences between the groups were observed in several other characteristics, including GWG, duration of gestation, and supplemental vitamin $\mathrm{D}$ intake.

We investigated whether pregnancy $25(\mathrm{OH}) \mathrm{D}$ concentration differed between mothers with $(n=81)$ and without GDM $(n=639)$ (Fig. 1$)$ in a crude model and in a model adjusted for season, maternal age, education and prepregnancy BMI. Adjusted analysis confirmed no difference in mean \pm SEM pregnancy $25(\mathrm{OH}) \mathrm{D}$ concentration between GDM and non-GDM mothers $(81.7 \pm 2.3$ vs $81.7 \pm 0.8 \mathrm{nmol} / \mathrm{L}, P=0.99)$. Similarly in UCB, the adjusted analysis showed no difference in $25(\mathrm{OH}) \mathrm{D}$ concentrations in infants born to women with and without GDM (79.1 \pm 2.3 vs $80.1 \pm 0.8 \mathrm{nmol} / \mathrm{L}, P=0.69)$ (Fig. 1 ). These results remained when only those who had undergone OGTT were included: pregnancy and UCB 25(OH)D concentrations were similar in GDM $(n=80)$ and non-GDM mothers $(n=323)(P=0.94$ and $P=0.43$, respectively).

We further tested for possible associations between pregnancy $25(\mathrm{OH}) \mathrm{D}$ concentration and OGTT results with a univariate regression model. We observed no association between pregnancy $25(\mathrm{OH}) \mathrm{D}$ and fasting plasma glucose (B -0.00; 95\% CI -0.00, 0.00; $P=0.54$ ), 1 -h glucose (B $0.00 ; 95 \%$ CI $-0.01,0.01 ; P=0.53$ ) or 2 -h glucose (B -0.00; 95\% CI -0.01, 0.01; $P=0.54$ ).

The prevalence of vitamin $\mathrm{D}$ deficiency $[25(\mathrm{OH}) \mathrm{D}<$ $50 \mathrm{nmol} / \mathrm{L}]$ during pregnancy was similar between mothers with or without GDM [4.9\% (4/81) vs 3.3\% (21/642), $P=0.51]$. However, more GDM mothers were vitamin D deficient at the delivery compared with non-GDM mothers [7.4\% $(6 / 81)$ vs $2.8 \%(18 / 642)(P=0.042)]$. However, of 


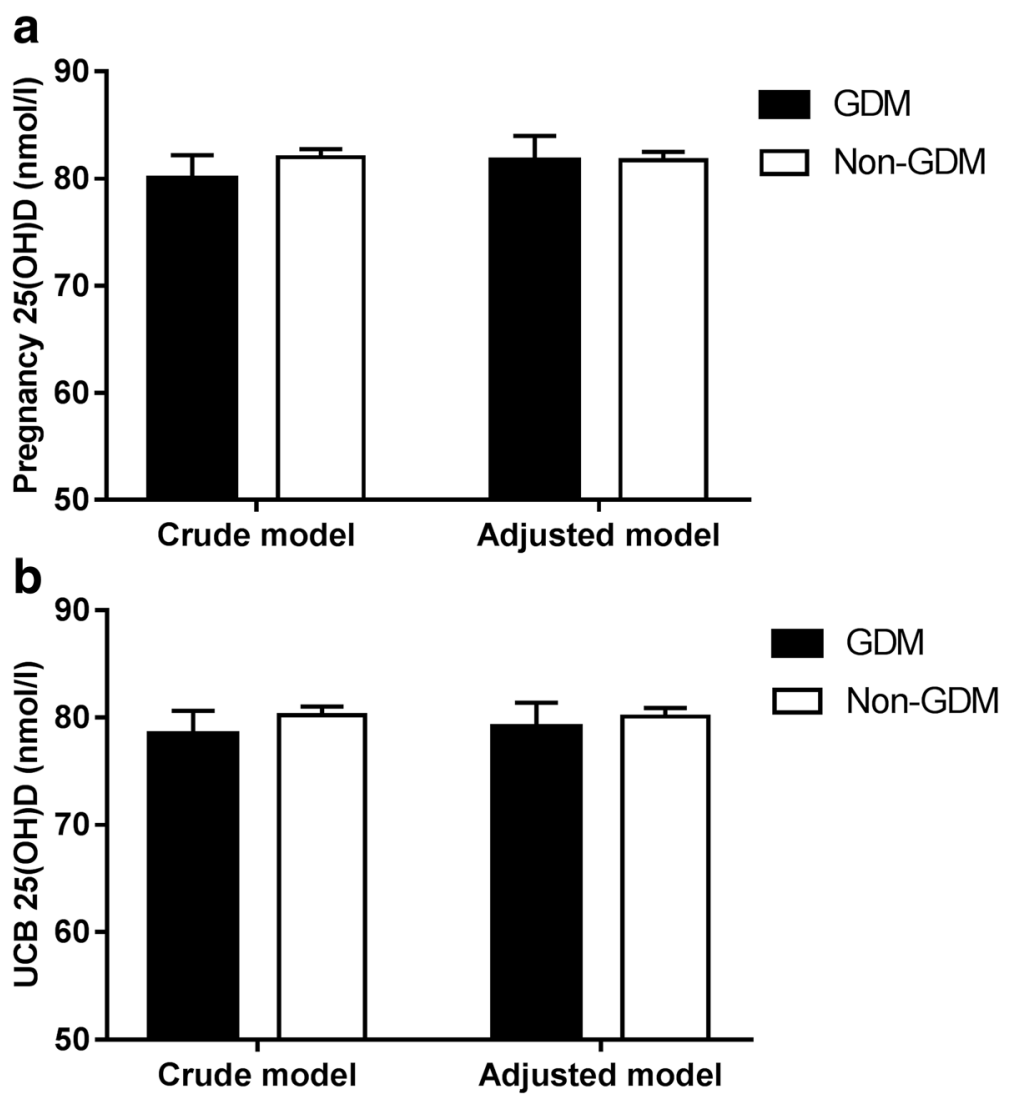

Fig. 1 Maternal vitamin $\mathrm{D}$ status and gestational diabetes mellitus. Adjusted mean $\pm \mathrm{SEM}$ values of pregnancy $25(\mathrm{OH}) \mathrm{D}(\mathbf{a})$ and $U \mathrm{CB} 25(\mathrm{OH}) \mathrm{D}$ concentration (nmol/L) (b) in GDM and non-GDM mothers. Adjustments are for season, maternal age, education and prepregnancy BMI. Maternal 25(OH)D concentrations were similar between non-GDM and GDM mothers. Abbreviations: 25(OH)D, 25-hydroxy vitamin D; UCB, umbilical cord blood; GDM, gestational diabetes mellitus

these six deficient GDM-mothers five (83\%) were smokers, and correspondingly in non-GDM mothers four out of eighteen were smokers $(24 \%)(P=0.018)$.

\section{Maternal 25(OH)D and newborn birth size}

The effect of maternal factors on birth size in fully adjusted models is presented in Table 2 and Fig. 2. Neither pregnancy $25(\mathrm{OH}) \mathrm{D}$ nor UCB $25(\mathrm{OH}) \mathrm{D}$ concentrations were related to birth length or ponderal index. As compared to mothers with suboptimal pregnancy $25(\mathrm{OH}) \mathrm{D}$, mothers with optimal pregnancy $25(\mathrm{OH}) \mathrm{D}$ had heavier newborns $(P=0.010)$, but this positive association was not verified in linear regression (B 0.00; 95\% CI $-0.00,0.01 ; P=0.16$ ). Newborn head circumference was larger in those with suboptimal UBC $25(\mathrm{OH}) \mathrm{D}$ compared with mothers with optimal UCB $25(\mathrm{OH}) \mathrm{D}(P=0.003)$. Further, linear regression confirmed the inverse association between UCB 25(OH)D and head circumference (B -1.74; 95\% CI -3.25, -0.23; $P=0.024)$. These results did not change after adjusting for mode of delivery (vaginal, vacuum assisted or caesarean section). Prepregnancy BMI, GWG, and parity had independent effects on birth size (Table 2 and Fig. 2).

\section{Discussion}

The primary focus of this work was to determine whether 25(OH)D concentration differs between mothers with and without GDM, and whether vitamin D status affects birth size in normal-birth-weight infants. GDM was diagnosed in $11 \%$ of mothers in our cohort. Almost all mother-child pairs (97\%) were vitamin D sufficient $[25(\mathrm{OH}) \mathrm{D} \geq 50 \mathrm{nmol} / \mathrm{L}]$, and about half of the motherchild pairs had optimal vitamin $\mathrm{D}$ status $[25(\mathrm{OH}) \mathrm{D} \geq$ $80 \mathrm{nmol} / \mathrm{L}]$. Maternal 25(OH)D concentrations were similar in GDM and non-GDM mothers. Interestingly, pregnancy vitamin $\mathrm{D}$ status associated positively with birth weight, but an inverse association was observed between newborn vitamin D status and head circumference at birth.

$\mathrm{Lu}$ et al. (2016) concluded in their meta-analysis that maternal vitamin $\mathrm{D}$ insufficiency $(<50 \mathrm{nmol} / \mathrm{L}$ or $<75 \mathrm{nmol} / \mathrm{L}$ ) was associated with greater risk of GDM [6]. However, they suggested that this applied only in developed countries and when no adjustments for confounders were made [6]. In our study, maternal vitamin D concentrations were similar in non-GDM and GDM 
Table 2 Independent effect of maternal factors on birth size ${ }^{a}$

\begin{tabular}{|c|c|c|c|c|c|}
\hline \multirow[b]{2}{*}{ Maternal factors } & \multicolumn{2}{|c|}{ Birth weight (SDS) } & \multirow{2}{*}{$\begin{array}{l}\text { Birth length (SDS) } \\
p \text { value }\end{array}$} & \multirow{2}{*}{$\begin{array}{l}\text { Head circumference }(\mathrm{SDS})^{\mathrm{b}} \\
p \text { value }\end{array}$} & \multirow{2}{*}{$\begin{array}{l}\text { Ponderal index }(z \text {-score })^{c} \\
p \text { value }\end{array}$} \\
\hline & $n$ & $p$ value & & & \\
\hline Prepregnancy BMI & & 0.020 & 0.201 & 0.364 & 0.719 \\
\hline Underweight & 19 & $-0.49 \pm 0.17$ & $-0.36 \pm 0.19$ & $-0.34 \pm 0.22$ & $-0.12 \pm 0.23$ \\
\hline Normal weight & 494 & $-0.30 \pm 0.03$ & $-0.23 \pm 0.04$ & $-0.14 \pm 0.04$ & $-0.01 \pm 0.05$ \\
\hline Overweight & 117 & $-0.13 \pm 0.07$ & $-0.12 \pm 0.08$ & $-0.04 \pm 0.09$ & $0.08 \pm 0.09$ \\
\hline Obese & 44 & $-0.05 \pm 0.12$ & $-0.01 \pm 0.13$ & $0.03 \pm 0.14$ & $0.08 \pm 0.16$ \\
\hline Gestational weight gain & & $<0.001$ & 0.006 & 0.186 & 0.505 \\
\hline Inadequate & 164 & $-0.43 \pm 0.06$ & $-0.37 \pm 0.07$ & $-0.23 \pm 0.07$ & $-0.05 \pm 0.08$ \\
\hline Adequate & 261 & $-0.28 \pm 0.05$ & $-0.20 \pm 0.05$ & $-0.11 \pm 0.06$ & $-0.02 \pm 0.06$ \\
\hline Excessive & 242 & $-0.12 \pm 0.05$ & $-0.09 \pm 0.06$ & $-0.05 \pm 0.06$ & $0.07 \pm 0.07$ \\
\hline Prepregnancy smoking & & 0.021 & 0.227 & 0.093 & 0.173 \\
\hline Yes & 101 & $-0.43 \pm 0.08$ & $-0.30 \pm 0.09$ & $-0.27 \pm 0.10$ & $-0.13 \pm 0.11$ \\
\hline No & 573 & $-0.23 \pm 0.03$ & $-0.18 \pm 0.04$ & $-0.09 \pm 0.04$ & $0.03 \pm 0.04$ \\
\hline Maternal education & & 0.972 & 0.670 & 0.721 & 0.634 \\
\hline Higher & 513 & $-0.26 \pm 0.03$ & $-0.19 \pm 0.04$ & $-0.11 \pm 0.04$ & $-0.00 \pm 0.05$ \\
\hline Lower & 161 & $-0.26 \pm 0.06$ & $-0.23 \pm 0.07$ & $-0.14 \pm 0.08$ & $0.04 \pm 0.08$ \\
\hline Parity & & $<0.001$ & $<0.001$ & 0.007 & 0.027 \\
\hline Nullipara & 431 & $-0.40 \pm 0.04$ & $-0.32 \pm 0.04$ & $-0.20 \pm 0.05$ & $-0.05 \pm 0.05$ \\
\hline Secundipara & 185 & $-0.03 \pm 0.05$ & $-0.05 \pm 0.06$ & $-0.03 \pm 0.07$ & $0.18 \pm 0.07$ \\
\hline Multipara & 58 & $0.04 \pm 0.10$ & $0.22 \pm 0.11$ & $0.17 \pm 0.12$ & $-0.07 \pm 0.13$ \\
\hline Gestational diabetes mellitus & 0.063 & & 0.559 & 0.351 & 0.075 \\
\hline Yes & 76 & $-0.10 \pm 0.09$ & $-0.15 \pm 0.10$ & $-0.02 \pm 0.11$ & $0.21 \pm 0.12$ \\
\hline No & 598 & $-0.28 \pm 0.03$ & $-0.21 \pm 0.03$ & $-0.13 \pm 0.04$ & $-0.02 \pm 0.04$ \\
\hline Pregnancy 25(OH)D concentration & & 0.010 & 0.095 & 0.398 & 0.236 \\
\hline Suboptimal (<80 nmol/L) & 333 & $-0.34 \pm 0.04$ & $-0.26 \pm 0.05$ & $-0.15 \pm 0.05$ & $-0.04 \pm 0.06$ \\
\hline Optimal ( $\geq 80 \mathrm{nmol} / \mathrm{L})$ & 341 & $-0.19 \pm 0.04$ & $-0.15 \pm 0.05$ & $-0.09 \pm 0.05$ & $0.05 \pm 0.06$ \\
\hline UCB 25(OH)D concentration & 0.149 & & 0.486 & 0.003 & 0.234 \\
\hline Suboptimal (<80 nmol/L) & 369 & $-0.22 \pm 0.04$ & $-0.18 \pm 0.04$ & $-0.02 \pm 0.05$ & $0.05 \pm 0.05$ \\
\hline Optimal ( $\geq 80 \mathrm{nmol} / \mathrm{L})$ & 305 & $-0.31 \pm 0.04$ & $-0.23 \pm 0.05$ & $-0.24 \pm 0.05$ & $-0.05 \pm 0.06$ \\
\hline
\end{tabular}

25(OH)D 25-hydroxy vitamin D, UCB umbilical cord blood

Values are adjusted mean \pm SEM. $p$ value is in bold when statistically significant

${ }^{a}$ Adjusted for maternal height and other listed maternal factors as changing covariates

b Two values are missing from analyses

c Adjusted for gestational age

mothers, and there was no linear association between vitamin D concentrations and OGTT results. However, we observed that vitamin D deficiency at delivery was more prevalent in mothers with GDM compared with nonGDM mothers, but this was not marked during pregnancy. This finding was possibly confounded by smoking, which was more prevalent in the deficient GDM mothers compared with deficient non-GDM mothers. Nevertheless due to small number of deficient mothers we could not investigate this reliably. In accordance with other studies, our results imply that in a vitamin D sufficient population, the association between 25(OH)D and GDM may not exist $[8,21,22]$. Similarly, Josefson et al. (2016) stated that maternal fasting glucose or GDM status was not associated with pregnancy $25(\mathrm{OH}) \mathrm{D}$, which in their study was on average $93 \mathrm{nmol} / \mathrm{L}$ [23].

GDM is a multifactorial disease involving various risk factors, for example lifestyle factors, obesity, rapid weight gain and predisposing genetic factors. Furthermore, some of these factors are related to or co-exist with poor vitamin D status [24, 25], which further increases the challenge when dissecting independent effect. It is possible that in previous studies where no adjustment for confounding factors was performed, the association between 25(OH)D and GDM reflects shared factors such as an unhealthy lifestyle or adiposity [26]. 


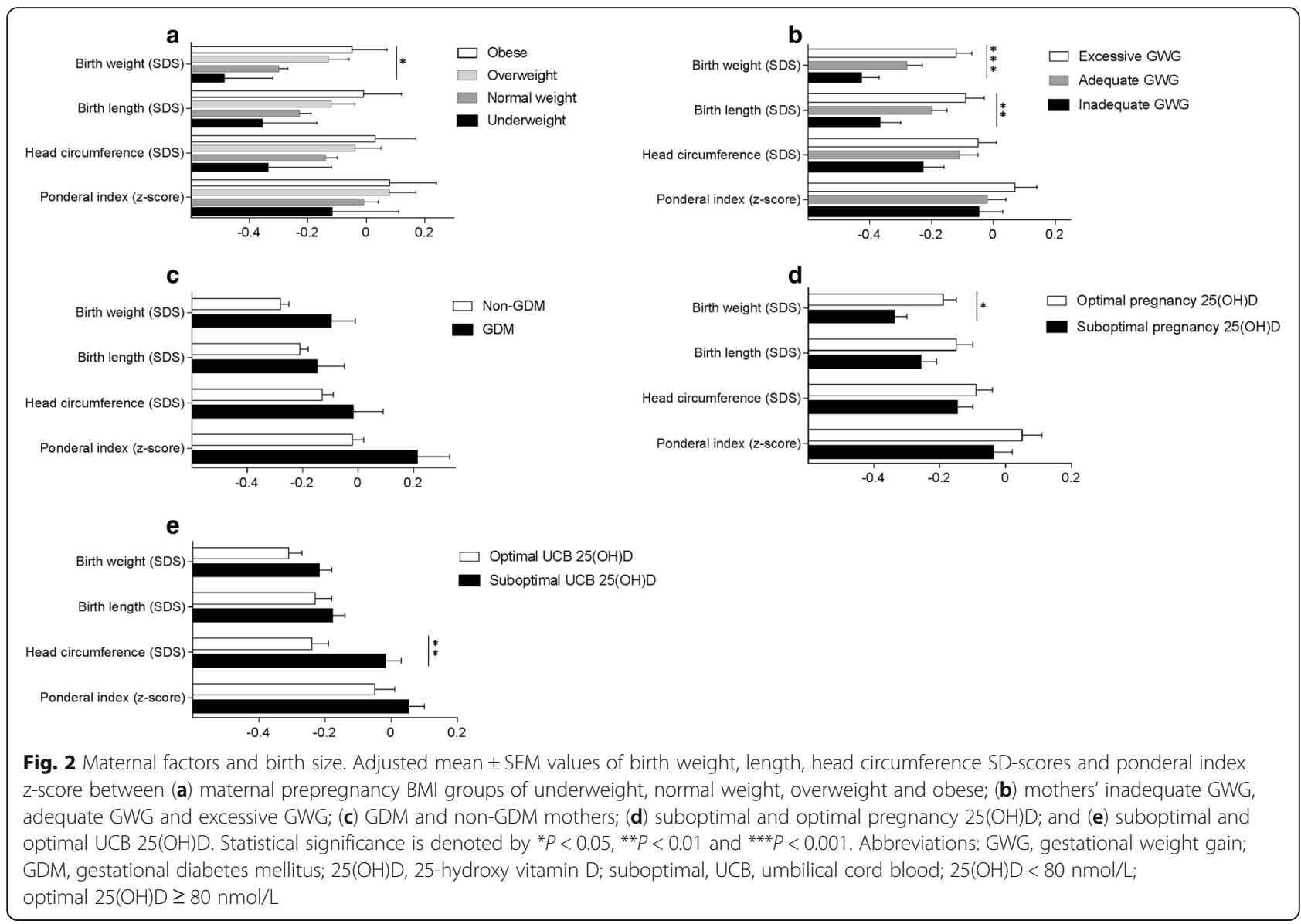

Yet, contrary to many studies, associations between high $25(\mathrm{OH}) \mathrm{D}$ and GDM have been reported [27, 28]. Although a biological mechanism between low vitamin D status and diabetes is plausible [29], only a few interventions have been conducted, and these have not proved an effect of vitamin D supplementation on risk of GDM [30].

Maternal vitamin D status associated with birth size: pregnancy $25(\mathrm{OH}) \mathrm{D}$ showed a positive association towards birth weight, but UCB 25(OH)D an inverse association with head circumference, while only the inverse association with head circumference was verified with linear model. Harvey et al. (2014) concluded that modest evidence exist for a positive relation between maternal vitamin D status and birth weight [31]. Some earlier studies have shown that severe maternal vitamin D deficiency associates with smaller head circumference at birth [32, 33], yet some have not $[34,35]$. In agreement with our findings, others have discovered that mothers with higher vitamin D concentration have infants with smaller head circumference at birth [36, 37]. However, the clinical relevance, if any, of the inverse relationship between maternal vitamin D status and head circumference at birth remains unexplained. It is unknown whether this reflects differences in brain size or in skull bones' structure, and needs to be explored in future studies. The mean difference in head circumference was 0.22 SD units between the groups with optimal and suboptimal UCB 25OHD. A possible explanation for this might be a U-shaped association between maternal vitamin $\mathrm{D}$ concentration and fetal outcomes in a population with sufficient vitamin D status. We have previously suggested the U-shaped association between $25(\mathrm{OH}) \mathrm{D}$ concentration and inflammatory biomarkers in cord blood [5].

We have collected a homogenous cohort of Caucasian mothers from the capital region of Finland representing mothers without regular medication and their newborns who were born at term with normal birth weight. In many previous studies, participants had various ethnic backgrounds which could affect both vitamin D status and their risk of GDM [7, 38]. A strength of the present study lies in the recruitment of subjects, which took place in a single hospital, enabled standardised data collection and covered all seasons. However, a multi-centre study might have resulted in a wider variety of socioeconomic backgrounds.

A challenge in previous studies on vitamin D status and GDM has been the lack of relevant adjustments, for example adjustments for BMI and smoking status [6]. In the present study, we have systematically investigated 
confounders between groups, and adjusted for those when applicable. The threshold for defining vitamin D deficiency and the diagnostic criteria for GDM vary between studies, which might affect the results and complicate the comparison of studies. A further limitation is that the OGTT was not performed on all mothers, and a slight possibility exists that the actual prevalence of GDM might be underestimated. Yet, our main results were repeated in a subgroup analysis of only those women to whom an OGTT was performed. In addition, the prevalence of GDM was in accordance with the national statistics [12]. However, in a cross-sectional setting causal relationships cannot be determined.

\section{Conclusion}

In summary, maternal vitamin $\mathrm{D}$ concentration was similar in mothers with and without GDM in a vitamin D sufficient population. Furthermore, we found an inverse association between UCB 25(OH)D and infant head circumference. The clinical relevance of this finding remains unsolved and needs to be considered in future studies. Sufficient maternal vitamin D status, specified as $25(\mathrm{OH}) \mathrm{D}$ above $50 \mathrm{nmol} / \mathrm{L}$, seems a threshold value, above which the physiological requirements of pregnancy are achieved. Our findings suggest that an adequate maternal vitamin status have been achieved in Finland. However, randomised controlled trials are required in specific risk groups of vitamin D deficiency to clarify if vitamin $\mathrm{D}$ supplementation affects the risk of GDM.

\section{Additional file}

Additional file 1: DEQAS July 2014 25-hydroxyvitamin D positive bias. (PDF $655 \mathrm{~kb}$ )

\section{Abbreviations}

25(OH)D: 25-hydroxy vitamin D concentration; GDM: Gestational diabetes mellitus; GWG: Gestational weight gain; UCB: Umbilical cord blood

\section{Acknowledgements}

We are grateful to our research nurses Sirpa Nolvi, Rhea Paajanen, Nea Boman and Päivi Turunen for their assistance in data collection. Laboratory technician Sari Lindén is acknowledged for her valuable work. We acknowledge the midwives and laboratory technicians at Kätilöopisto Maternity Hospital for obtaining umbilical cord blood samples. We are grateful to Professor Kari Teramo, MD, PhD, (Department of Obstetrics and Gynaecology, University of Helsinki and Helsinki University Hospital) for his valuable comments on the manuscript. Most importantly, we thank all the families that participated in this study.

\section{Funding}

Research project funding sources are Academy of Finland, Governmental Subsidy for Clinical Research, Foundation for Pediatric Research, Finska Läkaresällskapet, Folkhälsan Research Foundation, Sigrid Jusélius Foundation, Stiftelsen Dorothea Olivia, Karl Walter och Jarl Walter Perkléns Minne, and Päivikki and Sakari Sohlberg Foundation.

\section{Availability of data and materials}

The datasets analysed during the current study are not publicly available due the VIDI intervention trial which has not been published yet, but are available from the corresponding author on reasonable request.

\section{Authors' contributions}

The authors' contributions are as follows: HHH, HTV, OMM and SA designed the study; HHH, HTV, EMH, ME, JR, SMV, TKH and OMH participated in acquisition of the data; $\mathrm{HHH}$ analysed the data; $\mathrm{HHH}$ and HTV wrote the first draft of the manuscript. All of the authors critically revised the manuscript and approved the final version.

\section{Ethics approval and consent to participate}

Written informed consent was obtained from the parents at recruitment. This study was conducted according to the guidelines laid down in the Declaration of Helsinki. Ethical approval was obtained from the Research Ethics Committee of the Hospital District of Helsinki and Uusimaa (107/13/03/03/2012). The project protocol is registered in ClinicalTrials.gov in November 8, 2012 (NCT01723852).

\section{Consent for publication}

Not applicable.

\section{Competing interests}

The authors declare that they have no competing interests.

\section{Publisher's Note}

Springer Nature remains neutral with regard to jurisdictional claims in published maps and institutional affiliations.

\section{Author details}

${ }^{1}$ Children's Hospital, University of Helsinki and Helsinki University Hospital, Biomedicum 2 C, P.O. Box 705, 00020 HUS Helsinki, Finland. ${ }^{2}$ Folkhälsan Research Center, Haartmaninkatu 8, P.O.Box 63, 00014 Helsinki, Finland. ${ }^{3}$ Center for Molecular Medicine, Karolinska Institute and Clinical Genetics, Karolinska University Hospital, 17176 Solna, Stockholm, Sweden.

Received: 8 February 2017 Accepted: 24 November 2017

Published online: 15 December 2017

\section{References}

1. Viljakainen HT, Saarnio E, Hytinantti T, Miettinen M, Surcel H, Makitie O, Andersson S, Laitinen K, Lamberg-Allardt C. Maternal vitamin D status determines bone variables in the newborn. J Clin Endocrinol Metab. 2010;95(4):1749-57.

2. Itkonen ST, Lamberg-Allardt C. Food fortification as a means to increase vitamin D intake. Br J Nutr. 2016;115(11):2075-6.

3. Cashman KD, Dowling KG, Skrabakova Z, Kiely M, Lamberg-Allardt C, Durazo-Arvizu RA, Sempos CT, Koskinen S, Lundqvist A, Sundvall J, Linneberg A, Thuesen B, Husemoen LL, Meyer HE, Holvik K, Gronborg IM, Tetens I, Andersen R. Standardizing serum 25-hydroxyvitamin D data from four Nordic population samples using the vitamin D standardization program protocols: shedding new light on vitamin D status in Nordic individuals. Scand J Clin Lab Invest. 2015;75(7):549-61.

4. Raulio S, Erlund I, Männistö S, Sarlio-Lähteenkorva S, Sundvall J, Tapanainen $H$, Vartiainen $E$, Virtanen S. Successful nutrition policy: improvement of vitamin D intake and status in Finnish adults over the last decade. Eur J Pub Health. 2016; doi:10.1093/eurpub/ckw154.

5. Rosendahl J, Holmlund-Suila E, Helve O, Viljakainen $\mathrm{H}$, Hauta-Alus $\mathrm{H}$, Valkama S, Enlund-Cerullo M, Hytinantti T, Tervahartiala T, Sorsa T, Makitie O, Andersson S. 25-hydroxyvitamin D correlates with inflammatory markers in cord blood of healthy newborns. Pediatr Res. 2017; doi:10.1038/pr.2017.9.

6. Lu M, Xu Y, LV L, Zhang M. Association between vitamin D status and the risk of gestational diabetes mellitus: a meta-analysis. Arch Gynecol Obstet. 2016:293(5):959-66.

7. Burris HH, Camargo CA Jr. Vitamin D and gestational diabetes mellitus. Curr Diab Rep. 2014;14(1):451. -013-0451-3

8. Loy SL, Lek N, Yap F, Soh SE, Padmapriya N, Tan KH, Biswas A, Yeo GS, Kwek K, Gluckman PD, Godfrey KM, Saw SM, Muller-Riemenschneider F, Chong YS, Chong MF, Chan JK. Growing up in Singapore towards healthy outcomes (GUSTO) study group: Association of Maternal Vitamin D Status with glucose tolerance and caesarean section in a multi-ethnic Asian cohort: the growing up in Singapore towards healthy outcomes study. PLoS One. 2015;10(11):e0142239.

9. American Diabetes Association. Diagnosis and Classification of Diabetes. Diabetes Care. 2013;36(Supplement 1):S67-74.

10. Ferrara A. Increasing prevalence of gestational diabetes mellitus: a public health perspective. Diabetes Care. 2007;30(Suppl 2):S141-6. 
11. Buckley BS, Harreiter J, Damm P, Corcoy R, Chico A, Simmons D, Vellinga A, Dunne F, Core Investigator DALI. Group: gestational diabetes mellitus in Europe: prevalence, current screening practice and barriers to screening A review. Diabet Med. 2012;29(7):844-54.

12. Vuori E, Gissler M. Official Statistics of Finland. Health 2015. National Institute for Health and Welfare: Perinatal statistics: parturients, deliveries and newborns 2014. 2015;19:5.

13. Damm P, Houshmand-Oeregaard A, Kelstrup L, Lauenborg J, Mathiesen ER, Clausen TD. Gestational diabetes mellitus and long-term consequences for mother and offspring: a view from Denmark. Diabetologia. 2016;59(7):1396-9.

14. Harder T, Rodekamp E, Schellong K, Dudenhausen JW, Plagemann A. Birth weight and subsequent risk of type 2 diabetes: a meta-analysis. Am J Epidemiol. 2007;165(8):849-57.

15. Weinert LS, Silveiro SP. Maternal-fetal impact of vitamin d deficiency: a critical review. Matern Child Health J. 2015;19(1):94-101.

16. Thuesen B, Husemoen L, Fenger M, Jakobsen J, Schwarz P, Toft U, Ovesen L, Jorgensen $T$, Linneberg A. Determinants of vitamin $D$ status in a general population of Danish adults. Bone. 2012;50(3):605-10.

17. Henry HL, Bouillon R, Norman AW, Gallagher JC, Lips P, Heaney RP, Vieth R, Pettifor JM, Dawson-Hughes B, Lamberg-Allardt CJ, Ebeling PR. 14th vitamin D workshop consensus on vitamin D nutritional guidelines. J Steroid Biochem Mol Biol. 2010;121(1-2):4-6.

18. Heaney RP, Dowell MS, Hale CA, Bendich A. Calcium absorption varies within the reference range for serum 25-hydroxyvitamin D. J Am Coll Nutr. 2003;22(2):142-6.

19. Kaaja R, Alenius H, Kinnunen $T$, Komulainen J, Peränen N, Rönnemaa T, Saramies J, Soukka H, Teramo K, Vuorela P, Vääräsmäki M. 2013 [current care guidelines - gestational diabetes] Käypä hoito -suositus - Raskausdiabetes. Available from: http://www.kaypahoito.fi/web/english/guidelineabstracts/ guideline?id=ccs00047. Accessed 15 May 2016.

20. Pihkala J, Hakala T, Voutilainen P, Raivio K. Characteristic of recent fetal growth curves in Finland. Duodecim. 1989;105(18):1540-6.

21. Burris HH, Rifas-Shiman SL, Kleinman K, Litonjua AA, Huh SY, Rich-Edwards JW, Camargo CA Jr, Gillman MW. Vitamin D deficiency in pregnancy and gestational diabetes mellitus. Am J Obstet Gynecol. 2012;207(3):182.e1-8.

22. Schneuer FJ, Roberts CL, Guilbert C, Simpson JM, Algert CS, Khambalia AZ, Tasevski V, Ashton AW, Morris JM, Nassar N. Effects of maternal serum 25hydroxyvitamin D concentrations in the first trimester on subsequent pregnancy outcomes in an Australian population. Am J Clin Nutr. 2014:99(2):287-95.

23. Josefson JL, Reisetter A, Scholtens DM, Price HE, Metzger BE, Langman CB, HAPO Study Cooperative. Research group: maternal BMI associations with maternal and cord blood vitamin D levels in a north American subset of hyperglycemia and adverse pregnancy outcome (HAPO) study participants. PLoS One. 2016;11(3):e0150221.

24. Pereira-Santos M, Costa PR, Assis AM, Santos CA, Santos DB. Obesity and vitamin D deficiency: a systematic review and meta-analysis. Obes Rev. 2015;16(4):341-9.

25. Vimaleswaran KS, Berry DJ, Lu C, Tikkanen E, Pilz S, Hiraki LT, Cooper JD, Dastani Z, Li R, Houston DK, Wood AR, Michaelsson K, Vandenput L, Zgaga L, Yerges-Armstrong LM, McCarthy MI, Dupuis J, Kaakinen M, Kleber ME, Jameson K, Arden N, Raitakari O, Viikari J, Lohman KK, Ferrucci L, Melhus H, Ingelsson E, Byberg L, Lind L, Lorentzon M, Salomaa V, Campbell H, Dunlop M, Mitchell BD, Herzig KH, Pouta A, Hartikainen AL, Genetic investigation of anthropometric traits-GIANT consortium, Streeten EA, Theodoratou E, Jula A, Wareham NJ, Ohlsson C, Frayling TM, Kritchevsky SB, Spector TD, Richards JB, Lehtimaki T, Ouwehand WH, Kraft P, Cooper C, Marz W, Power C, Loos RJ, Wang TJ, Jarvelin MR, Whittaker JC, Hingorani AD, Hypponen E. causal relationship between obesity and vitamin D status: bi-directional Mendelian randomization analysis of multiple cohorts. PLoS Med. 2013;10(2):e1001383.

26. Autier P, Boniol M, Pizot C, Mullie P, Vitamin D. Status and ill health: a systematic review. Lancet Diabetes Endocrinol. 2014;2(1):76-89.

27. Nobles CJ, Markenson G, Chasan-Taber L. Early pregnancy vitamin D status and risk for adverse maternal and infant outcomes in a bi-ethnic cohort: the behaviors affecting baby and you (B.A.B.Y.) study. Br J Nutr. 2015;114(12):2116-28.

28. Farrant HJ, Krishnaveni GV, Hill JC, Boucher BJ, Fisher DJ, Noonan K, Osmond C, Veena SR, Fall CH, Vitamin D. Insufficiency is common in Indian mothers but is not associated with gestational diabetes or variation in newborn size. Eur J Clin Nutr. 2009;63(5):646-52

29. Mathieu C, Vitamin D. Diabetes: where do we stand? Diabetes Res Clin Pract. 2015:108(2):201-9.

30. De-Regil LM, Palacios C, Lombardo LK, Pena-Rosas JP, Vitamin D. Supplementation for women during pregnancy. Cochrane Database Syst Rev. 2016;1:CD008873.
31. Harvey NC, Holroyd C, Ntani G, Javaid K, Cooper P, Moon R, Cole Z, Tinati T, Godfrey K, Dennison E, Bishop NJ, Baird J, Cooper C, Vitamin D. Supplementation in pregnancy: a systematic review. Health Technol Assess. 2014;18(45):1-190.

32. Miliku K, Vinkhuyzen A, Blanken LM, McGrath JJ, Eyles DW, Burne TH, Hofman A, Tiemeier H, Steegers EA, Gaillard R, Jaddoe WW. Maternal vitamin $D$ concentrations during pregnancy, fetal growth patterns, and risks of adverse birth outcomes. Am J Clin Nutr. 2016;103(6):1514-22.

33. Song SJ, Si S, Liu J, Chen X, Zhou L, Jia G, Liu G, Niu Y, Wu J, Zhang W, Zhang J, Vitamin D. Status in Chinese pregnant women and their newborns in Beijing and their relationships to birth size. Public Health Nutr. 2013;16(4):687-92.

34. Kiely M, O'Donovan SM, Kenny LC, Hourihane JO, Irvine AD, Murray DM, Vitamin D. Metabolite concentrations in umbilical cord blood serum and associations with clinical characteristics in a large prospective mother-infant cohort in Ireland. J Steroid Biochem Mol Biol. 2017;167:162-8.

35. Shor DB, Barzel J, Tauber E, Amital H. The effects of maternal vitamin D on neonatal growth parameters. Eur J Pediatr. 2015;174(9):1169-74.

36. Rodriguez A, Garcia-Esteban R, Basterretxea M, Lertxundi A, Rodriguez-Bernal C, Iniguez C, Rodriguez-Dehli C, Tardon A, Espada M, Sunyer J, Morales E. Associations of maternal circulating 25-hydroxyvitamin D3 concentration with pregnancy and birth outcomes. BJOG. 2015;122(12):1695-704.

37. Hanieh S, Ha TT, Simpson JA, Thuy TT, Khuong NC, Thoang DD, Tran TD, Tuan T, Fisher J, Biggs BA. Maternal vitamin D status and infant outcomes in rural Vietnam: a prospective cohort study. PLoS One. 2014;9(6):e99005.

38. Hunt KJ, Schuller KL. The increasing prevalence of diabetes in pregnancy. Obstet Gynecol Clin N Am. 2007;34(2):173-99. vii

\section{Submit your next manuscript to BioMed Central and we will help you at every step:}

- We accept pre-submission inquiries

- Our selector tool helps you to find the most relevant journal

- We provide round the clock customer support

- Convenient online submission

- Thorough peer review

- Inclusion in PubMed and all major indexing services

- Maximum visibility for your research

Submit your manuscript at www.biomedcentral.com/submit
Biomed Central 